\title{
PYRIDOXINE ANALYSIS BY HIGH PERFORMANCE LIQUID CHROMATOGRAPHY AND VALIDATION IN FORTIFIED MILK POWDER
}

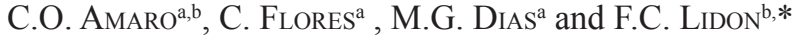

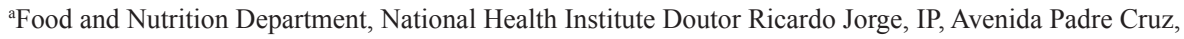 \\ 1649-016 Lisbon. Portugal \\ ${ }^{b}$ Earth Sciences Department, Faculty of Sciences and Technology of New University of Lisbon, Campus da \\ Caparica, 2829-516 Caparica. Portugal
}

(Received: 27 November 2012; accepted: 15 March 2013)

\begin{abstract}
Vitamin $B_{6}$ analysis by reverse-phase high performance liquid chromatography and its validation in milk powder prompted this study. The calibration curves for pyridoxal, pyridoxamine and pyridoxine were evaluated and method precision and accuracy assessed. It was found that the working range was adequate for all the analytes. The analytical procedure was verified by testing the enzymatic efficiency, precision and accuracy. In milk powder samples pyridoxine was the only vitamer found in quantities above the considered limit of quantification and the accuracy showed Z-scores lower than 2. Uncertainty estimation based on method validation results was $0.066 \mathrm{mg} / 100 \mathrm{~g}$, for a vitamin $\mathrm{B}_{6}$ content of $0.61 \mathrm{mg} / 100 \mathrm{~g}$. It was concluded that the method is adequate for vitamin $\mathrm{B}_{6}$ quantification in powder milk.
\end{abstract}

Keywords: Method validation, HPLC, pyridoxine, pyridoxal, pyridoxamine, vitamin $\mathrm{B}_{6}$

Vitamin $\mathrm{B}_{6}$ vitamers (pyridoxine (PN), pyridoxal (PL) and pyridoxamine (PM), and their 5 ' phosphate esters - PNP, PLP and PMP) are metabolically interconverted by phosphorylation, oxidation and amination reactions. As nonphosphorylated vitamers cross membranes more readily than their phosphorylated analogs, phosphorylation appears to be an important mean of retaining the vitamin at an intracellular level (COMBS, 1992). PLP is the active form of the vitamin in tissues (Bowling, 2011), interacting as prosthetic group of a large number of pyridoxine-dependent enzymes (COUltate, 2009) that catalyze more than 100 reactions in human metabolism (SPINNEKER et al., 2007).

The water soluble vitamin $\mathrm{B}_{6}$, essential for human nutrition, is widely distributed in foods, prevailing in meat, grains (especially wheat), vegetables and nuts (CoMBs, 1992). PLP predominates in animal based foods, whereas plant products mostly contain PN, PM and their phosphorylated forms. Conjugated vitamers of vitamin $\mathrm{B}_{6}$, in the form of PN-glycosides, have also been isolated from plant based foods, but with lower bioavailability than the six principal vitamers; a relative value of $58 \%$ has recently been suggested for PN-glycosides in humans (Russell, 2000). For the fortification of foods with vitamin $\mathrm{B}_{6}$ the hydrochloride salt of PN is the unique available form (Russell, 2000).

Even though the recommended intake might increase with the amount of protein in the diet (VINÃs et al., 2004), the optimal daily intake of vitamin $B_{6}$ is 1.2 and $1.5 \mathrm{mg} /$ day for women and men, respectively. Thus, as food composition tables are one of the main tools to

\footnotetext{
* To whom correspondence should be addressed.

Phone:+351 212948 30; fax:+351 212954 461; e-mail:fjl@fct.unl.pt
} 
assess the population's nutrient intake, validation of the analytical methods that quantify nutrients in food must be ensured, namely through evaluation of accuracy, precision and measurement uncertainty. Due to the photosensitivity of vitamin $\mathrm{B}_{6}$, subdued light analysis must be carried out. The interaction between temperature and $\mathrm{pH}$ must be considered, because non-phosphorylated vitamers are only heat stable under acidic conditions (RusselL, 2000). Some phosphorylated forms are only weakly fluorescent, however, PN, PL and PM display native fluorescence whose intensity is $\mathrm{pH}$-dependent (BALL, 1998), enabling fluorimetric detection without column derivatization when the analytical method includes a dephosphorylation step.

It is essential that laboratories have adequate criteria to demonstrate, through validation, that test methods are reliable. A reverse-phase high performance chromatography method for the analysis of vitamin $\mathrm{B}_{6}$ through the quantification of PM, PN and PL was developed and evaluated following the European Standard EN (2005). The validation methodology also considered the European standards ISO (1990, 2001), ISO (1994a, b), and ISO/IEC (2005) to assess calibration curve parameters, precision and accuracy. Studies were conducted in powdered milk matrices.

\section{Materials and methods}

\subsection{Equipment}

The HPLC system consisted of a Waters 2695 Separations Module equipped with a sample cooler, a column heater/cooler and a Waters 2475 Multi-Wavelength, coupled to a fluorescence detector. Chromatographic data were analyzed using Empower software (Waters, Milford, MA, USA).

\subsection{Samples}

The infant milk powder NIDINA 1 (Nestlé, Portugal) for 0 to 6 months old infants, with a nominal value for vitamin $B_{6}$ of $0.390 \mathrm{mg} / 100 \mathrm{~g}$ of powder, was used to test the precision of the method. Infant milk formula Babybio for 0 to 6 months was used to test enzyme activity. Milk powder (BIPEA-20-3317-2520-0090), cereals (BIPEA-20-317-3220-0095) and breakfast cereals (FAPAS-2160, 2166 and 2172) from proficiency test programs were tested to evaluate the accuracy of the method and to estimate the measurement uncertainty.

\subsection{Analytical methodology}

1.3.1. Reagents and standards. All chemicals were at least of analytical grade; methanol was HPLC-grade and ultrapure water was obtained from a Milli-Q system (Millipore, Bedford, MA, USA). Standard stock solutions of PM, PL and PN were obtained after dissolution $\left(500 \mu \mathrm{g} \mathrm{ml}^{-1}\right)$ of pyridoxine hydrochloride (Sigma, Ref. P9755), pyridoxamine dihydrochloride (Sigma, Ref. P9380) and pyridoxal hydrochloride (Alfa Aesar, Ref. A17855) with purity $\geq 98 \%$, in $\mathrm{HCl} 0.1 \mathrm{~mol} \mathrm{l}^{-1}$. The concentrations of these standard stock solutions were determined by spectrophotometry, using the appropriated conditions and molecular extinction coefficients accordingly to the EN (2005). Solutions were stored at $-20{ }^{\circ} \mathrm{C}$ for 2 months, as stated in the same European Standard. Intermediate stock solutions of 10 and $1 \mu \mathrm{g} \mathrm{ml}^{-1}$ were daily prepared by dilution with $\mathrm{HCl} 0.1 \mathrm{~mol} \mathrm{l}^{-1}$. By diluting $1 \mu \mathrm{g} \mathrm{ml}^{-1}$ solutions with water, six mixed working solutions were prepared within the range of $0.04-0.09 \mu \mathrm{g} \mathrm{ml}^{-1}$. Enzymatic treatment was performed with potato acid phosphatase (Calbiochem, Ref. 
524529). PM-P solution (5 $\mu \mathrm{g} \mathrm{ml}^{-1}$ ) was prepared from pyridoxamine-5' -phosphate (Sigma, ref. 82890).

1.3.2. Samples preparation. Duplicate samples (1 to $10 \mathrm{~g}$ for solid samples) were submitted to acid hydrolysis with $\mathrm{HCl} 0.1 \mathrm{~mol} \mathrm{l}^{-1}$ for $30 \mathrm{~min}$ in an autoclave at $121^{\circ} \mathrm{C}$. After cooling to room temperature, the $\mathrm{pH}$ was adjusted to 4.8 with sodium acetate solution $2.5 \mathrm{~mol} \mathrm{l}^{-1}$. The solution was diluted to $100 \mathrm{ml}$ with water, and filtered through a qualitative paper filter. To transform the phosphorylated forms of vitamin $\mathrm{B}_{6}$ in the three free vitamers (PM, PL and PN), the filtrate was submitted to enzymatic treatment. Acid phosphatase $(9 \mathrm{mg})$ was added to $10 \mathrm{ml}$ of the filtrate and overnight incubated at $37{ }^{\circ} \mathrm{C}$. After cooling to room temperature, the $\mathrm{pH}$ was adjusted to 3 and the solution was diluted to $20 \mathrm{ml}$ with distilled water. Aliquots were filtered through $0.45 \mu \mathrm{m}$ membrane filters, prior to injection. A reagent blank was included in all batches to correct for any vitamin present in the enzyme solutions.

1.3.3. Chromatographic conditions and quantification. Separation was performed at $37^{\circ} \mathrm{C}$ using an isocratic solution of sulphuric acid of $0.015 \mathrm{~mol} \mathrm{l}^{-1}$, containing $0.005 \mathrm{~mol} \mathrm{l}^{-1}$ of trichloroacetic acid, with a flow rate of $1.5 \mathrm{ml} \mathrm{min}^{-1}$, on a Phenomenex Synergi Hidro RP $80 \mathrm{R}$ column $(250 \mathrm{~mm} \times 4.6 \mathrm{~mm})$ with a $4 \mu \mathrm{m}$ particle size, fitted with a $4 \mathrm{~mm} \times 3 \mathrm{~mm}$ guard column (Ref. AJO7511). Injection volume was $50 \mu 1$ and fluorimetric detection was performed at an excitation wavelength of $290 \mathrm{~nm}$ and an emission wavelength of $390 \mathrm{~nm}$.

Peak areas were used for quantification through the external calibration method. For each vitamer, two injections of each of the six levels of calibration standards $(0.04,0.05$, 0.06, 0.070 .08 and $0.09 \mu \mathrm{g} \mathrm{m}^{-1}$ ) were plotted. The vitamin content of the sample was expressed as $\mathrm{mg} / 100 \mathrm{~g}$ of pyridoxine and given by:

$\left(\right.$ Vitamin $\left.\mathrm{B}_{6}\right)=1.006 \times(\mathrm{PM})+1.012 \times(\mathrm{PL})+(\mathrm{PN})$, where the coefficients are related to molecular weight ratios of PN to PM or PL, PM, PL and PN sample concentrations were corrected by subtracting the values obtained for the reagent blank.

\subsection{Validation methodology}

According to the ISO (1990, 2001), for each vitamer a linear calibration curve and a working range with acceptable intra-day precision was established, being thereafter the calibration curves performance assessed. After obtaining acceptable calibration curves, the applied quantities of acid phosphatase were tested according to the EN (2005) to determine the precision and accuracy.

1.4.1. Calibration curves. Linearity was assessed through the application of Mandel's fitting test and then working ranges were established to assure that the quantified limit did not exceed the lowest calibration point. The homoscedasticity of the signals obtained from the two extreme calibration standards of ten independent curves, considering intermediate precision conditions, were also tested. The average of the signals obtained for both injections of each level was considered to be the value of the curve for that level. Homogeneity of variance was tested through an $F$-test.

From the mean of the values obtained from these ten curves, the following performance parameters of the curves were calculated: correlation coefficient (r), sensibility (slope), residual standard deviation, method standard deviation $\left(\mathrm{S}_{\mathrm{m}}\right.$, being $\mathrm{S}_{\mathrm{m}}=\mathrm{S}_{\mathrm{y} / \mathrm{x}} / \mathrm{b}$, where $\mathrm{S}_{\mathrm{y} / \mathrm{x}}$ is the 
residual standard deviation and $\mathrm{b}$ the slope of the regression line obtained from the calibration plot), method coefficient of variation $\left(\mathrm{V}_{\mathrm{m}}\right.$, being $\mathrm{V}_{\mathrm{m}}=\mathrm{S}_{\mathrm{m}} / \overline{\mathrm{x}} \times 100$, where $\overline{\mathrm{x}}$ is the mean concentration from the standard solutions of the calibration experiment).

1.4.2. Enzyme efficiency. Animal sources of vitamin $\mathrm{B}_{6}$, as milk, contain phosphorylated vitamers. In order to obtain a simple analytical method avoiding post-column derivatization, phosphorylated forms need to be enzymatically converted to the dephosphorylated forms in order to be quantified. Accordingly to the EN (2005), phosphatase efficiency should be tested in pork, potato puree or whole meal. Taking into account that milk is an animal source, pork was chosen to test enzyme efficiency.

Two different quantities, 9 and $18 \mathrm{mg}$, of acid phosphatase were used to test the enzyme efficiency in dephosphorylation of $10 \mathrm{~g}$ of pork meat. The enzyme quantity was considered adequate when the vitamin $B_{6}$ quantified in both test samples remained equivalent.

In addition, based on the standard EN (2008), enzyme efficiency was tested. Three different samples were tested: B: $4 \mathrm{ml}$ of PM-P solution $\left(5 \mu \mathrm{g} \mathrm{ml}^{-1}\right)$; C: $2.0 \mathrm{~g}$ of infant milk formula Babybio; and D: $4 \mathrm{ml}$ of PM-P solution $\left(5 \mu \mathrm{g} \mathrm{ml}^{-1}\right)+2.0 \mathrm{~g}$ of infant milk formula Babybio. The complete analytical procedure was applied to samples $\mathrm{C}$ and $\mathrm{D}$ and the same procedure, without enzyme addition, was applied to sample B.

1.4.3. Analytical limits. Analytical limits of the overall procedure were calculated based on calibration curves. The quantification limit (LOQ) is calculated through the formula $\mathrm{LOQ}=\left(10 \times \mathrm{S}_{\mathrm{y} / \mathrm{x}}\right) / \mathrm{b}$ and the detection limit $(\mathrm{LOD})$ through $\mathrm{LOD}=\left(3.3 \times \mathrm{S}_{\mathrm{y} / \mathrm{x}}\right) / \mathrm{b}$, where $\mathrm{S}_{\mathrm{y} / \mathrm{x}}$ is the residual standard deviation and $\mathrm{b}$ the slope of the regression line. These sample limits were calculated using the maximum sample weight.

1.4.4. Precision and accuracy. To evaluate the precision of the method, three series of six samples in three different days were assayed, being expressed as repeatability relative standard deviation $\mathrm{RSD} \%$ and as intermediate precision relative standard deviation $\mathrm{RSD} \%$. The highest of the three day RSD $\%$ was considered as method repeatability relative standard deviation $\mathrm{RSD} \%$. The intermediate precision standard deviation $\left(\mathrm{SD}_{\mathrm{IP}}\right)$ was calculated from:

$$
\mathrm{SD}_{\mathrm{IP}}=\sqrt{\frac{1}{\mathrm{n}-1} \sum_{\mathrm{k}-1}^{\mathrm{N}}\left(\mathrm{y}_{\mathrm{k}}-\overline{\mathrm{y}}\right)^{2}}
$$

where, $\mathrm{n}$ is the number of assays in one series; $\mathrm{N}$ is the total number of assays; $\mathrm{y}_{\mathrm{k}}$ is the value obtained at assay $\mathrm{k}$ of $\mathrm{N}$; $\overline{\mathrm{y}}$ is the average of the $\mathrm{N}$ assays.

Precision of the method was accepted when both RSD $\%$ were below $10 \%$.

To evaluate accuracy, two operators tested one reference material, NIST, and one proficiency test, BIPEA, both milk samples, adopting as a criterion that results were considered acceptable when $\mid Z$-score $\mid \leq 2$. Additionally other proficiency test samples, BIPEA and FAPAS cereals, were tested accordingly to the same criterion.

1.4.5. Uncertainty estimation. Measurement uncertainty evaluation was done based on validation data, including precision and accuracy studies. All terms were combined accordingly to the uncertainty combination rules (EURACHEM/CiTAC GUIDE, 2000) to obtain the expanded uncertainty using a coverage factor of 2 , corresponding to a confidence level of 0.05 . 


\section{Results and discussion}

The implemented and extensively validated analytical method brought some advantages. The $100 \%$ aqueous mobile phase reduces the use of organic solvents used by other authors (VALLS et al., 2001; KALL, 2003; VINÃS et al., 2004; GATTI \& GIOIA, 2005) reducing the costs for solvents, environment, and residues treatment. Besides, it does not require post-derivatization column as other methods (SAmPSON et al., 1995, KALL, 2003; VIñ̃s et al., 2004; GatTi \& GioIA, 2005). The HPLC conditions, including a column chosen based on its resistance to water, present a lower run time (11 $\mathrm{min}$ ) than others referred in the literature: $20 \mathrm{~min}$ (SAMPSON et al., 1995) and $30 \mathrm{~min}$ (GATTI \& GioiA, 2005). A good peak resolution (Fig. 1 and 2) was also obtained. The good results obtained for vegetable reference material indicate that after appropriate validation the application of the method could be broadened.

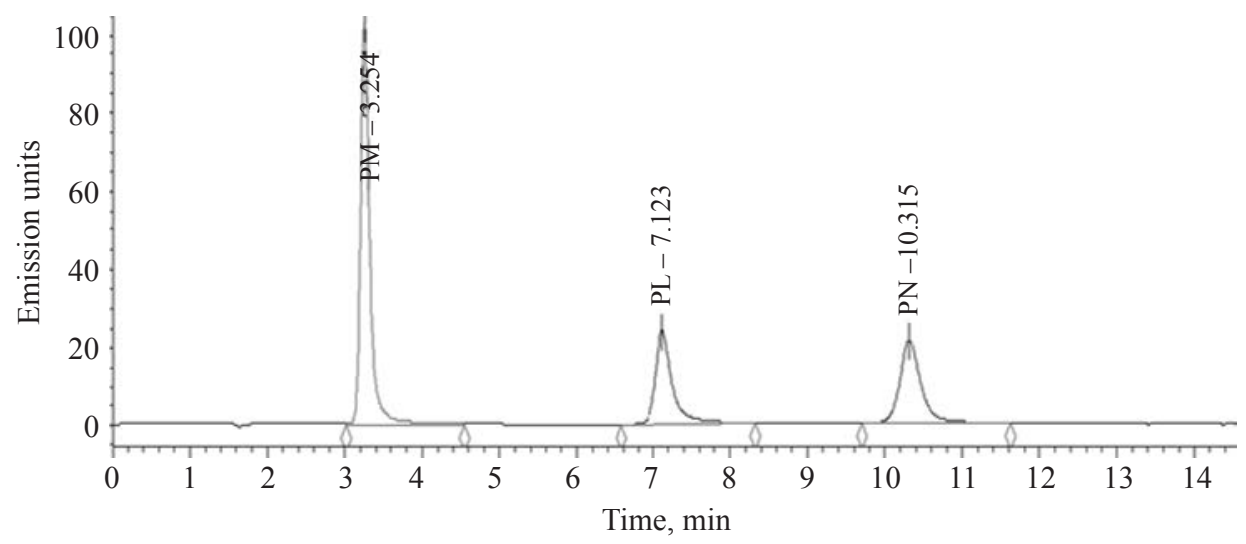

Fig. 1. Chromatogram of a mixed standard solution containing PM, PL and PN $\left(0.09 \mu \mathrm{g} \mathrm{ml}^{-1}\right)$. (Retention times in min, 3.2, 7.1 and 10.3 for PM, PL and PN, respectively)

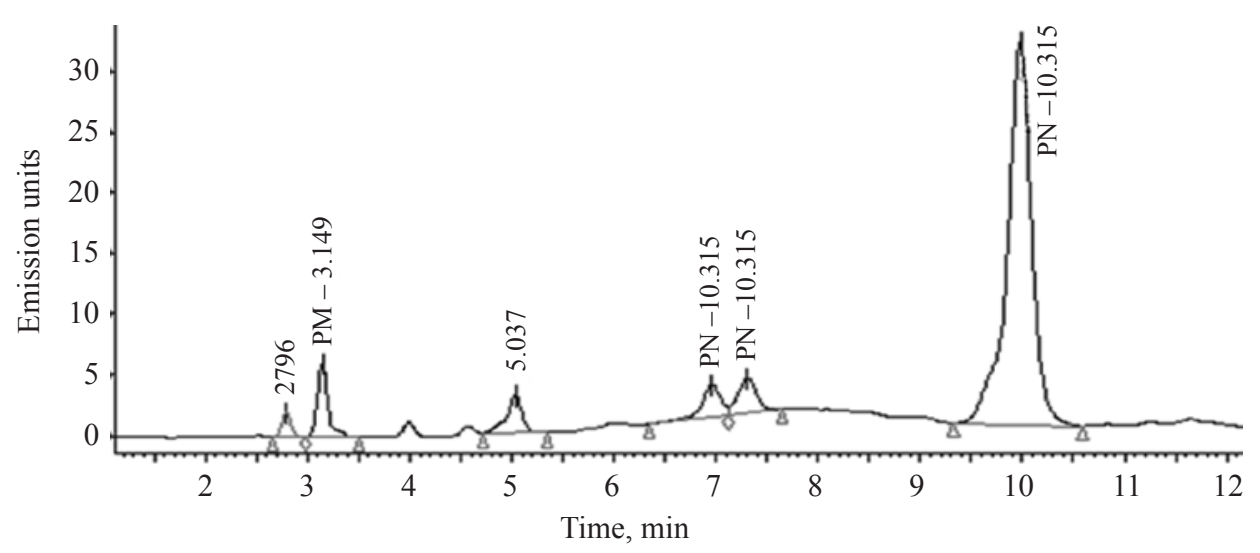

Fig. 2. Chromatogram of the milk powder sample employed in the precision tests. (Retention times in min, 3.1, 7.3 and 9.9, for PM, PL and PN, respectively) 


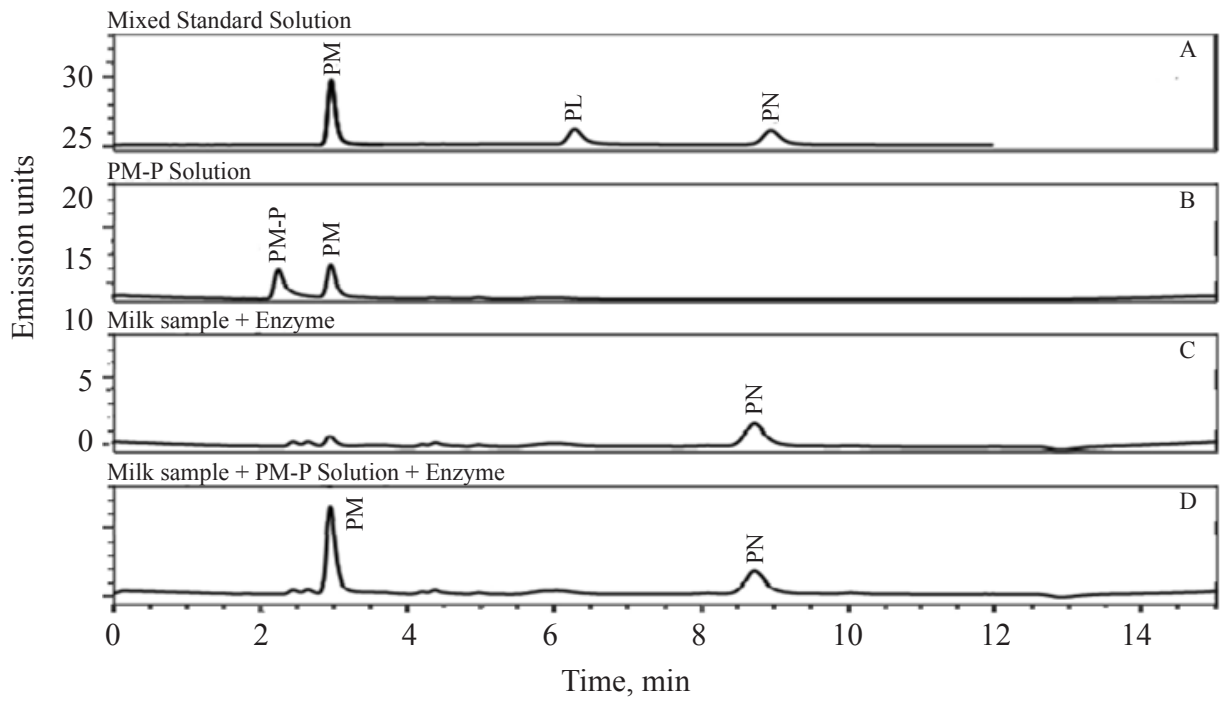

Fig. 3. Chromatograms of a mixed standard solution (A), PM-P solution (B); milk sample + enzyme (C); and milk sample + PM-P solution + enzyme (D)

\subsection{Calibration curves}

The statistical verification of linearity through Mandel's test for the calibration curves of PM, PL and PN (Fig. 1) proved that the quadratic regression model did not fit the experimental data better than the linear model (Table 1). The established working concentration range ( 0.04 to $0.09 \mu \mathrm{g} \mathrm{ml}^{-1}$ ) was considered adequate for all the analytes, as the existence of homoscedasticity, between the signals of both extreme calibration points, was demonstrated (Table 2). In all cases, the calculated quantification limits also stayed below the lowest calibration point (Table 2), indicating that the working range was well adjusted. In both tests all the $F$ values also were lower than the tabulated $F$ values (Table 1), pointing that both models fitted the range of concentrations. Slope values (Table 2) showed considerably more sensitivity for PM than for PL and PN.

Table 1. Calculated $F$ values for calibration curves fitness tests, for the concentration range of $0.04-0.09 \mu \mathrm{g} \mathrm{ml}-1$

\begin{tabular}{ccc}
\hline Analyte & Mandel's test $^{\mathrm{a}, \mathrm{c}}$ & Homoscedasticity test $^{\mathrm{b}, \mathrm{c}}$ \\
\hline PM & 0.59 & 3.42 \\
PL & 2.06 & 1.60 \\
PN & 1.22 & 1.37 \\
\hline
\end{tabular}

a: $F$ tabulated value, $(1 ; n-3$ d.f. $)=10.56 ;$ b: $F$ tabulated value $(n-1 ; n-1$ d.f. $)=5.35 ;$ c: probability $=0.99 \%$ 
Table 2. Parameters of the mean values obtained from ten independent calibration curves of PM, PL and PN

\begin{tabular}{cccccccc}
\hline Analyte & $\mathrm{r}$ & $\mathrm{b}$ & $\mathrm{S}_{\mathrm{y} / \mathrm{x}}$ & $\mathrm{S}_{\mathrm{m}}$ & $\mathrm{V}_{\mathrm{m}}$ & LOQ $\left(\mu \mathrm{g} \mathrm{ml}^{-1}\right)$ & LOD $\left(\mu \mathrm{g} \mathrm{ml}^{-1}\right)$ \\
\hline PM & 0.9995 & $1.54 \mathrm{E}+08$ & $8.74 \mathrm{E}+4$ & $5.68 \mathrm{E}+4$ & 0.87 & 0.006 & 0.002 \\
PL & 0.9995 & $7.22 \mathrm{E}+07$ & $4.33 \mathrm{E}+4$ & $4.33 \mathrm{E}+4$ & 0.92 & 0.006 & 0.002 \\
PN & 0.9993 & $7.56 \mathrm{E}+07$ & $4.47 \mathrm{E}+4$ & $4.47 \mathrm{E}+4$ & 0.91 & 0.006 & 0.002 \\
\hline
\end{tabular}

( $\mathrm{r}$ : correlation coefficient; $\mathrm{b}$ : sensibility; $\mathrm{S}_{\mathrm{y} / \mathrm{x}}$ : residual standard deviation; $\mathrm{S}_{\mathrm{m}}$ : method standard deviation; $\mathrm{V}_{\mathrm{m}}$ : method coefficient of variation; LOQ: limit of quantification; LOD: Limit of detection)

\subsection{Enzyme efficiency}

Considering that the amount of vitamin $\mathrm{B}_{6}$ obtained after doubling the potato acid phosphatase quantity did not increase (Table 3 ), all the phosphorylated vitamers were converted, showing that $9 \mathrm{~g}$ of enzyme are appropriate.

Table 3. Enzyme efficiency test

\begin{tabular}{lccc}
\hline Sample & Sample weight $(\mathrm{g})$ & Acid phosphatase $(\mathrm{mg})$ & Vitamin $_{6}(\mathrm{mg} / 100 \mathrm{~g})$ \\
\hline Pork meat 1 & 10.0198 & 9 & 0.38 \\
Pork meat 2 & 10.0155 & 18 & 0.37 \\
\hline
\end{tabular}

The results obtained for enzyme efficient tests using PM-P are presented in Figure 3. Accordingly to results all PM-P added to the sample was dephosphorylated, confirming that potato acid phosphatase is suitable for desphosphorylation, under the procedure conditions.

\subsection{Analytical limits, precision and accuracy}

The analytical limits, LOQ and LOD, obtained from the calibration curves are presented in Table 2. As LOQ values were below the lower solution concentration used to construct the calibration curve, the LOQ adopted were the first point of the calibration curves, $0.04 \mu \mathrm{g}$ $\mathrm{ml}^{-1}$, which corresponds to the analytical limits presented in Table 4 .

Table 4. Calculated analytic limits of PM, PL and PN

\begin{tabular}{lcc}
\hline Vitamer & LOQ $(\mathrm{mg} / 100 \mathrm{~g})$ & LOD $(\mathrm{mg} / 100 \mathrm{~g})$ \\
\hline PM & 0.02 & 0.0067 \\
PL & 0.02 & 0.0067 \\
PN & 0.02 & 0.0067 \\
\hline
\end{tabular}

In the milk powder samples of NIDINA 1, PN was the only vitamer found in quantities above the considered LOQ (Table 4) and consequently the only one considered for the final result (Fig. 2). However, PM was consistently detected in quantities below the calculated 
LOQ. The mean value obtained for vitamin $\mathrm{B}_{6}(\mathrm{n}=18)$ was $0.61 \mathrm{mg} / 100 \mathrm{~g}$. The repeatability and intermediate precision relative standard deviations RSD $\%$ were $5.8 \%$ and $4.9 \%$, respectively (being therefore accepted as they followed the established criteria, $\operatorname{RSD}_{0}<10 \%$ ). In both cases, by comparing with reference values calculated by Horwitz equation (HoRwITZ et al., 1980), Horrat values obtained were less than 2, which indicate that the method has an adequate precision. The repeatability limit obtained for a probability of $95 \%$ was $0.095 \mathrm{mg} / 100 \mathrm{~g}$, meaning that this is the maximum concentration difference admissible between two replicates.

For all samples, the obtained $\mid$ Z-score $\mid$ consistently remained lower than 2 (Table 5), which indicated that the method can be considered accurate for the considered matrices.

Table 5. Accuracy evaluation tests using two operators for BIPEA, FAPAS and NIST samples

\begin{tabular}{lcccc}
\hline Samples & \multicolumn{2}{c}{ Vitamin $\mathrm{B}_{6} \mu \mathrm{g} / 100 \mathrm{~g}$} & Z-SCORE & Operator \\
\cline { 2 - 3 } Milk powder & 1.47 & 1.42 & & \\
NiST 1849 & 1.51 & 1.42 & 0.7 & 1 \\
& 0.29 & 0.3 & 1.2 & 2 \\
(BIPEA-20-3317-2520-0090) & 0.25 & 0.3 & -0.2 & 1 \\
& & & -1.0 & 2 \\
Cereals & 2.33 & 2.86 & & 1 \\
(BIPEA-20-317-3220-0095) & 2.76 & 2.86 & -1.1 & 2 \\
& & & -0.2 & 1 \\
Breakfast cereals & 1.87 & 2.04 & -0.8 & 2 \\
FAPAS-2160 & 1.96 & 2.04 & -0.4 & 1 \\
FAPAS-2166 & 1.63 & 1.61 & -0.1 & \\
FAPAS-2172 & & & \\
\hline
\end{tabular}

\subsection{Uncertainty estimation}

Taking into account the estimated analytical measurement uncertainty $(0.066 \mathrm{mg} / 100 \mathrm{~g})$, the studied matrix had a vitamin $\mathrm{B}_{6}$ content of $0.61 \pm 0.07 \mathrm{mg} / 100 \mathrm{~g}$, for a confidence level of 0.05. Standard measurement uncertainty contributions were 0.043 and $0.023 \mathrm{mg} / 100 \mathrm{~g}$, respectively from precision and accuracy.

\section{Conclusion}

The analytical methodology described in this procedure for milk powder was validated, since all the parameters met the required validation criteria. For powdered milk used in accuracy tests, according to the validation tests, the working range remained adequate; however, in the matrix used in precision studies, PM concentration was lower than the LOQ. This indicated that an experimental verification of the theoretical limits, calculated from the calibration data or the validation of lower working range, for all vitamers may be useful. The vitamin $\mathrm{B}_{6}$ 
obtained in the milk powder analysed in the precision study $(0.61 \mathrm{mg} / 100 \mathrm{~g})$ was above the labelled value $(0.390 \mathrm{mg} / 100 \mathrm{~g})$. Concerning the analytical measurement uncertainty estimation, the results of vitamin $\mathrm{B}_{6}$ quantification for milk powder by the method presented should be reported with two significant figures.

Abbreviations: LOD: limit of detection; LOQ: limit of quantification; PL: pyridoxal; PLP: pyridoxal phosphate; PM: pyridoxamine; PMP: pyridoxamine phosphate; PN: pyridoxine; PNP: pyridoxine phosphate; RSD\%: relative standard deviation.

\section{References}

BaLl, G.F.M. (1998): Bioavailability and analysis of vitamins in foods. (1 ${ }^{\text {st }}$ ed.), Chapman \& Hall, London, p. 365. Bowling, F.G. (2011): Pyridoxine supply in human development. Semin. Cell Dev. Biol., 22, 611-618.

Combs. G.F. (1992): The vitamins, fundamental aspects in nutritional and health. $2^{\text {nd }}$ ed., Academic Press, New York, 528 pages.

Coultate, T.P. (2009): Food: The chemistry of its components, $5^{\text {th }}$ ed., Royal Society of Chemistry, U.K, 432 pages. EN (2008): Foodstuffs - Determination of vitamin b6 by HPLC. European Standard. No 14164

EN (2005): Foodstuffs - Determination of vitamin $B_{6}$, (including its glycosylated forms) by HPLC. European Standard. No 14663

Eurachem/Citac Guide (2000): Quantifying uncertainty in analytical measurement. CG4. $2^{\text {nd }}$ ed. Available from $<$ www.eurachem.ul.pt $>$.

Gatti, R. \& Gioia, M.G. (2005): Liquid chromatographic determination with fluorescence detection of B $_{6}$ vitamers and riboflavin in milk and pharmaceuticals. Anal. Chim. Acta, 538, 135-141.

Horwitz, W., Kamps, L.R. \& Boyer, K.W. (1980): Quality assurance in the analysis of foods and trace constituents. J. Assoc. Off. Anal. Chem., 63, 1344-1354.

ISO (1990): Water quality - calibration and evaluation of analytical methods and estimation of performance characteristics - Part 1: Statistical evaluation of the linear calibration function. International Standard. No 8466-1.

ISO (1994a): Accuracy (trueness and precision) of results - Part 1: general principles and definitions. International Standard. No 5725-1

ISO (1994b): Accuracy (trueness and precision) of results - Part 2: Basic method for the determination of repeatability and reproducibility of a standard measurement method. International Standard. No 5725, 2.

ISO (2001): Water quality - calibration and evaluation of analytical methods and estimation of performance characteristics - Part 2: Calibration strategy for non-linear second-order calibration. International Standard. No 8466-2.

ISO/IEC (2005): Requisitos gerais de competência para laboratórios de ensaio e calibração. (General requirements for the competence of testing and calibration laboratories.) International Standard. No 17025.

KALL, M.A. (2003): Determination of total vitamin $B_{6}$ in foods by isocratic HPLC: a comparison with microbiological analysis. Fd Chem., 82, 315-327.

Russell, F. (2000): Quantitative determination of water soluble vitamins. -in: Nollet, L.M.L. (Ed.) Food analysis by HPLC, $2^{\text {nd }}$ ed.,Marcel Dekker, New York, pp. 403-476.

SAmpson, D.A., Eoff, L.A., Yan, X.L. \& Lorenz, K. (1995): Analysis of free and glycosylated vitamin B ${ }_{6}$ in wheat by high-performance liquid chromatography. Cereal Chem., 72, 217-223.

Spinneker, A. A., Sola, R., Lemmen, V., Castillo, M.J., Pietrzik K. \& González-Gross, M. (2007): Vitamin B 6 status, deficiency and its consequences - an overview. Nutrición Hospitalaria, 22, 7-24.

Valls, F., Sancho, M.T.M., Fernández-Muiño, A. \& Checa, M.A. (2001): Determination of vitamin B 6 in cooked sausages. J. Agric. Fd Chem., 49, 38-41.

Vinãs, P., Balsalobre, N., López-Erroz, C. \& Hernández-Córdoba, M. (2004): Determination of vitamin B in foods using liquid chromatography with post-colunm derivatization fluorescence detection. Chromatographia, $59,381-386$. 